\title{
MEFV mutations in systemic JIA
}

N Aktay Ayaz*1, Y Bilginer1, E Yilmaz¹, M Ergüven², R Topaloglu1, A Bakkaloglu ${ }^{1}$ and S Ozen ${ }^{1}$

\begin{abstract}
Address: ${ }^{1}$ Hacettepe University Medical Faculty, Ankara, Turkey and ${ }^{2}$ Göztepe Education and Research Hospital, Istanbul, Turkey
* Corresponding author
\end{abstract}

\author{
from $15^{\text {th }}$ Paediatric Rheumatology European Society (PreS) Congress \\ London, UK. 14-17 September 2008 \\ Published: 15 September 2008 \\ Pediatric Rheumatology 2008, 6(SuppI I):P26 doi:I0.I I86/I546-0096-6-SI-P26
}

This abstract is available from: http://www.ped-rheum.com/content/6/SI/P26

(C) 2008 Aktay Ayaz et al; licensee BioMed Central Ltd.

\section{Background}

Systemic form of juvenile idiopathic arthritis (JIA) is regarded as an autoinflammatory disease. Certain genetic polymorphisms in genes coding inflammatory proteins have been associated with the disease. On the other hand mutations of the MEFV gene cause a monogenic autoinflammatory disease, Familial Mediterranean Fever (FMF).

In a previous study in adult rheumatoid arthritis 3 out of the 25 British patients who developed secondary amyloidosis had a mutation/polymorphism in the MEFV gene.

\section{Aim}

To analyse whether mutaions in the MEFV gene had an association with systemic JIA.

\section{Patients and methods}

MEFV mutations were screened in a total of 32 systemic JIA patients. All had been classified as systemic JIA according to the Durban JIA criteria. None had disease characteristics that met the Tel Hashomer criteria for the diagnosis of FMF.

\section{Results}

2 carrier for M694V and two patients who were homozygote for MEFV mutations. Both of these patients were among the most severe patients in the group. One had an excellent response to etanercept whereas the other was resistant to anti-TNF and other conventional treatments and had only a partial response to thalidomide. Although the number of severe mutations were increased in this small group of patients with systemic JIA the difference with the Turkish population did not reach statistical significance, but the disease causing mutation $(\mathrm{M} 694 \mathrm{~V})$ was significantly high in the patients with systemic JIA(p = $0.02)$.

\section{Conclusion}

However, the severe disease course in the aforementioned patients suggest that MEFV mutations may be a modifying genetic factor in systemic JIA. 